2018-11-30

\title{
Methanotrophy, Methylotrophy, the Human Body and Disease
}

\author{
Boden, Rich
}

http://hdl.handle.net/10026.1/16336

10.1007/978-3-030-15147-8_19

Springer Nature Switzerland

All content in PEARL is protected by copyright law. Author manuscripts are made available in accordance with publisher policies. Please cite only the published version using the details provided on the item record or document. In the absence of an open licence (e.g. Creative Commons), permissions for further reuse of content should be sought from the publisher or author. 


\section{Metadata of the chapter that will be visualized online}

\begin{tabular}{lll}
\hline Chapter Title & Methanotrophy, Methylotrophy, the Human Body, and Disease \\
\hline Copyright Year & 2019 & \\
\hline Copyright Holder & Springer Nature Switzerland AG & Boden \\
\hline Corresponding Author & Family Name & \\
& Particle & Rich \\
& Given Name & \\
Suffix & Division/Department & School of Biological and Marine \\
& Sciences, Faculty of Science and \\
& Engineering \\
& City & University of Plymouth \\
Country & Plymouth \\
Division/Department & UK \\
& Sustainable Earth Institute, Faculty of \\
& Organization/University & University of Plymouth \\
City & Plymouth \\
Country & UK \\
Email & rich.boden@plymouth.ac.uk \\
\hline
\end{tabular}

Abstract

Methylotrophic Bacteria use one-carbon $\left(\mathrm{C}_{1}\right)$ compounds as their carbon source. They have been known to be associated to the human body for almost 20 years as part of the normal flora and were identified as pathogens in the early 1990s in end-stage HIV patients and chemotherapy patients. In this chapter, I look at $\mathrm{C}_{1}$ compounds in the human body and exposure from the environment and then consider Methylobacterium spp. and Methylorubrum spp. in terms of infections and its role in breast and bowel cancers, Methylococcus capsulatus and its role in inflammatory bowel disease, and Brevibacterium casei and Hyphomicrobium sulfonivorans as part of the normal human flora. I also consider the abundance of methylotrophs from the Actinobacteria being identified in human studies and the potential bias of the ionic strength of culture media and the needs for future work. Within the scope of future work, I consider the need for the urgent assessment of the pathogenic, oncogenic, mutagenic, and teratogenic potential of Methylobacterium spp. and Methylorubrum spp. and the need to handle them at higher containment levels until more data are available. 


\title{
Methanotrophy, Methylotrophy, the Human Body, and Disease
}

\author{
Rich Boden
}

\section{Contents}

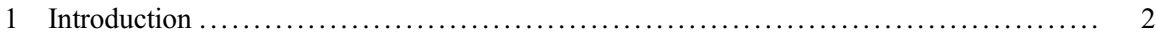

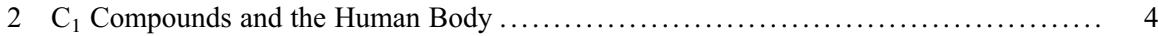

2.1 Exogenous Exposure of the Human Body to $\mathrm{C}_{1}$ Compounds ................. 4

2.2 Endogenous Exposure of the Human Body to $\mathrm{C}_{1}$ Compounds ................. 5

3 Methylotrophs Known to Be Associated with the Human Body $\ldots \ldots \ldots \ldots \ldots \ldots \ldots \ldots . \quad 7$

4 Methylobacterium and Methylorubrum spp................................. 8

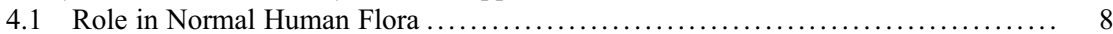

4.2 Role as Human Pathogens ............................................ 10

4.3 Potential Roles in Breast Cancer ......................................... 11

4.4 Potential Roles of Methylobacterium spp. and Methylorubrum spp. in Other Cancers 12

4.5 Perspectives ...................................................... 12

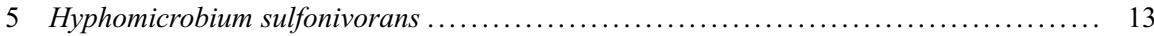

$6 \quad$ Brevibacterium casei ................................................... 13

7 Immune Modulation by Methylococcus capsulatus ............................... 14

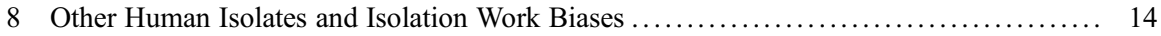

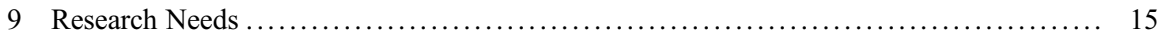

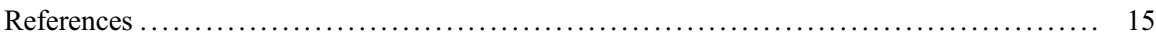

R. Boden $(\bowtie)$

School of Biological and Marine Sciences, Faculty of Science and Engineering, University of Plymouth, Plymouth, UK

Sustainable Earth Institute, Faculty of Science and Engineering, University of Plymouth, Plymouth, UK

e-mail: rich.boden@plymouth.ac.uk 


\section{Abstract}

Methylotrophic Bacteria use one-carbon $\left(\mathrm{C}_{1}\right)$ compounds as their carbon source. They have been known to be associated to the human body for almost 20 years as part of the normal flora and were identified as pathogens in the early 1990s in end-stage HIV patients and chemotherapy patients. In this chapter, I look at $\mathrm{C}_{1}$ compounds in the human body and exposure from the environment and then consider Methylobacterium spp. and Methylorubrum spp. in terms of infections and its role in breast and bowel cancers, Methylococcus capsulatus and its role in inflammatory bowel disease, and Brevibacterium casei and Hyphomicrobium sulfonivorans as part of the normal human flora. I also consider the abundance of methylotrophs from the Actinobacteria being identified in human studies and the potential bias of the ionic strength of culture media and the needs for future work. Within the scope of future work, I consider the need for the urgent assessment of the pathogenic, oncogenic, mutagenic, and teratogenic potential of Methylobacterium spp. and Methylorubrum spp. and the need to handle them at higher containment levels until more data are available.

\section{Introduction}

The methylotrophs are a functional guild of the Bacteria that can grow on organic one-carbon $\left(\mathrm{C}_{1}\right)$ compounds as their sole source of carbon and energy. $\mathrm{C}_{1}$ compounds do not contain carbon-carbon bonds, and thus every carbon-carbon bond must be made de novo. Historically, methylotrophy was considered to be a restricted and specialist metabolic mode that was only found in distinct taxonomic groups, but in the last decade (e.g., Boden et al. 2008), the range of "generalist" organisms displaying methylotrophic growth has increased. That said, on examination of any recent taxonomy articles of generalist heterotrophs being isolated, the reader will note a paucity of $\mathrm{C}_{1}$ compounds on the list of substrates examined - thus we probably have an underestimation of the diversity of methylotrophic organisms. The full gamut $\mathrm{C}_{1}$ compounds that occur in Nature or have been synthesized is vast, and not all of them have been examined for growth by the Bacteria - while the following list is exhaustive, it is no doubt incomplete: methane, methanol $(\mathrm{MeOH})$, dimethyl ether (DME), formaldehyde, formate, methanethiol (MeSH), methaneselenol $(\mathrm{MeSeH})$, methanetellurol $(\mathrm{MeTeH})$, thioformaldehyde, dimethyl sulfide (DMS), dimethyl sulfoxide (DMSO), dimethyl sulfone $\left(\mathrm{DMSO}_{2}\right)$, dimethyl disulfide (DMDS), dimethyl trisulfide (DMTS), dimethyl tetrasulfide (DMQS), methanesulfonate (MSA), hydroxymethanesulfinate (Rongalite), monomethylamine (MMA), dimethylamine (DMA), trimethylamine (TMA), trimethylamine $N$-oxide (TMAO), methyl chloride, methyl bromide, methyl fluoride, formamide, $N, N$ dimethylformamide, cyanamide, methanimine, diazomethane, carbon tetrachloride, carbon tetrabromide, carbon tetraiodide, iodoform, bromoform, chloroform, 
fluoroform, methylene fluoride, methylene chloride, methylene bromide, methylene iodide, various mixed halomethanes (e.g., dichlorodifluoromethane), methanesulfonyl chloride, hexamethylphosphoramide (HMPA), 1,3,5-trinitro-1,3,5-triazinane (RDX or hexogen), $N, N^{\prime}$-bis-(1H-tetrazol-5-yl)-hydrazine (HBT), 1,3,5,7tetranitro-1,3,5,7-tetrazocane (HMX or octogen), 2,4,6-trichloro-1,3,5-triazine (cyanuric chloride or TCT), 6-chloro- $N, N$-dimethyl-1,3,5-triazine-2,4-diamine, 1,3,5-triazine-2,4,6-triamine (melamine), 1,3,5,-triazine-2,4,6-triol (sym-triazinetriol), 1,3,5-triazine-2,4,6-trione (sym-triazinetrione), melamine-cyanurate (1:1 mix of melamine and sym-triazinetrione), 2-cyanoguanidine (DCD), isocyanic acid (carbamide), 1,3,5-triazine (vedita), 1,3,5-trioxane (trioxin), 1,3,5-trithiane (thioform), 1,3-diazetidine, $1 H$-tetrazole, and 1,3,5-trithiane-1,1,3,3,5,5-hexaoxide. Methyl iodide hydrolyzes spontaneously in water, as does methyl formate; thus these probably do not contribute directly to methylotrophic growth. Thioformaldehyde trimerizes into 1,3,5-trithiane spontaneously, and thus the former is probably not a growth substrate itself. Phosgene, urea, carbonyl sulfide, and carbon disulfide are also one-carbon compounds but are inorganic or are metabolized via carbon dioxide; thus while they support growth, it is by autotrophs (e.g., Thiobacillus thioparus). While not all of the $\mathrm{C}_{1}$ compounds listed above are found in Nature, their use as building blocks in organic chemistry, solvents, explosives, plastics, pesticides, etc., results in their exposure to humans and to the environment. Some are also formed within the human body from the breakdown of medications or poisons - such as those based on $1 \mathrm{H}$-tetrazole.

Methanotrophs are subset of methylotrophs that can grow on methane as a sole carbon source - for some reason this metabolic trait is relatively restricted - but methanotrophs range from being very restricted, apparently "only" growing on methane, methanol, and sometimes MMA (but they have seldom been tested on a truly wide range of substrates), to more generalist methanotrophs that grow on fatty acids and intermediates of Krebs' cycle.

The diversity of methylotrophs and methanotrophs has now been shown to include a diverse range of genera, including members of the classes Alphaproteobacteria (e.g., Paracoccus, Methylosinus, Methylobacterium, Methylorubrum, Xanthobacter), Betaproteobacteria (e.g., Methylophilus), Gammaproteobacteria (e.g., Methylococcus, Crenothrix, Klebsiella, Pseudomonas, Sphingomonas), Actinobacteria (e.g., Leifsonia, Mycobacterium, Gordonia, Rhodococcus), and classis incertae sedis in the phylum "Verrucomicrobia" (Candidatus Methylacidiphilum). In light of this, the potential for human-associated methylotroph diversity to be much higher than previously considered is vast. It is worth noting that the catabolism of the full range of one-carbon compounds is not fully understood - many enzymes have not been purified and pathways are only putative - this makes predictions of methylotrophic potential from human- or animal-associated metagenomic datasets very difficult even in 2018, and considerable biochemical and physiological studies are needed to understand the full gamut of methylotrophic catabolism. 


\section{$2 \quad C_{1}$ Compounds and the Human Body}

The human body produces $\mathrm{C}_{1}$ compounds directly or as a consequence of the action of normal microbial flora or pathogenic flora. Some genetic pathologies lead to an increase in the production of $\mathrm{C}_{1}$ compounds. Additionally, topical application of some $\mathrm{C}_{1}$ compounds in the form of "dietary supplements" or "alternative medicines" (e.g., $\mathrm{DMSO}, \mathrm{DMSO}_{2}$ ) occurs, as well as occupational exposure to $\mathrm{C}_{1}$ compounds from the diet and from exposure to, e.g., chemicals by laboratory researchers.

While not all $\mathrm{C}_{1}$ compounds are odorous, many are foul-smelling and can be detected at low levels, and thus have significant interest in terms of hygiene and the cosmetics industry, which has led to a significant number of studies determining various $\mathrm{C}_{1}$ compounds in body fluids, etc. The odor thresholds for $\mathrm{C}_{1}$ compounds include (ppb by volume) DMS (3.0), DMDS (2.2), MeSH (0.07), MMA (35.0), DMA (33.0), and TMA (0.032). For comparison (ppb by volume), hydrogen sulfide (0.5), acetic acid (6.0), and butyric acid (0.19) are in similar orders of magnitude (data from those curated by Wood and Kelly (2010) and Leonardos et al. (1969)).

\subsection{Exogenous Exposure of the Human Body to $C_{1}$ Compounds}

In this section I have outlined some of the major routes by which the human body can be exposed to exogenous $\mathrm{C}_{1}$ compounds or from consumption of precursors such as pectin. It is not intended to be exhaustive but to give the reader a flavor of the myriad routes to exposure.

\subsection{1 $C_{1}$ Exposure from the Diet}

Many foods are known to contain $\mathrm{C}_{1}$ compounds, including TMA and TMAO in fish and seafoods (the former produced from the latter by bacterial action, Bystedt et al. (1959)) and DMS in Allium spp. L. (garlic, leek, onions, etc., Amiri (2007) and Lawson et al. (1991)), Brassica spp. L. (cabbage, cauliflower, turnip, etc., Engel et al. (2002)), Solanum lycopersicum L. (tomato, Williams (1973)), Camellia sinensis L. (tea, Smet et al. (1998)), Zea mays var. rugosa L. (sweetcorn, Bills and Keenan (1968)), and Tuber spp. P.Micheli ex F.H.Wigg (truffles, Bellesia et al. (1996) and Talou et al. (1990)). Methanol is produced from pectin (a heteropolysaccharide from plant cell walls and used as a gelling agent in jams, etc. - found at particularly high concentrations in citrus peels, carrots, apples, and apricots) breakdown in the gut at a rate of about 10-20 mmol per day (Lindinger et al. 1997) and is also taken up from alcoholic drinks - for example, a $50 \mathrm{~mL}$ measure of brandy contains $2.5 \mathrm{mmol}$ methanol (Lindinger et al. 1997).

\subsection{2 $C_{1}$ Exposure from "Dietary Supplements" and "Alternative Medicines"}

Two $\mathrm{C}_{1}$ sulfur compounds have become marketed as "dietary supplements" $\left(\mathrm{DMSO}_{2}\right)$ or "alternative medicines" (DMSO) in the last 20 years. The former is sold as "methylsulfonylmethane" or MSM and is produced from waste from the 
Kraft paper process, as is DMSO, which is sold as an embrocation for use on stiff joints, etc. Thus far, peer-reviewed clinical trials have shown minor beneficial effect in some conditions (Usha and Naidu 2004), and in vitro studies have shown antioxidant potential in $\mathrm{DMSO}_{2}$. It has been shown as safe for consumption of $>2.5$ g per day with no ill effects. $\mathrm{DMSO}_{2}$-containing products currently marketed include toothpastes, mouthwashes, shampoos, etc., all of which could have implications for perturbing the methylotrophic body flora. It is worth noting that sports supplements containing choline are converted to TMA in the gut, and thus can be an indirect source of TMA from such products.

\subsection{3 $\quad C_{1}$ Exposure from the Environment and Occupational Exposure}

Formate (as formic acid) is produced by ants of the genus Formica L. (wood ants, Hoffman (2010)) and in the stinging hairs of Urtica dioica L. (the stinging nettle, Klaessen (2013)). It is also produced from soils in deciduous forests (Sanhueza and Andreae 1991) and probably from most soils, as is methane. Methylated amines and sulfur compounds are produced in various plants and in decaying animal tissue. DMS, DMSO, and $\mathrm{DSMO}_{2}$ are abundant in marine environments, in both the water and the atmosphere, as is MSA.

Occupational exposure is of course largely for individuals working in the laboratory sciences, where MeSH, DMS, DMSO, etc., can readily be absorbed through the skin (Ljunggren and Norberg (1948) and from the author's own experience: $5 \mathrm{~mL}$ of a $10 \mathrm{mM}$ DMS solution [totaling $50 \mu \mathrm{mol}$ DMS or $3.1 \mathrm{mg}$ ] spilt on the hand could be tasted for 16-24 h and was detectable in the odor of urine for $48 \mathrm{~h}$ !). TMA and DMA emitted during the making of solutions of their hydrochloride salts cling on the hair and skin for several hours. Solvents such as dichloromethane and carbon tetrachloride are used in the chemical industry and can be inhaled resulting in their transfer to the bloodstream or can be exposed to the skin. DMS and DMSO are produced in the Kraft paper process and workers can be exposed (Leach and Chung 1982). In addition to laboratory and chemical industry workers, there is exposure to DMS and methane at significant concentrations in swine and fowl farm workers (Kim et al. 2007; Tymczyna et al. 2007). In animal rendering plants, Maillard reactions in slaughterhouse waste heated to $>105{ }^{\circ} \mathrm{C}$ for tallow extraction result in production of high concentrations of DMS that workers may be exposed to (van Langenhove et al. 1982). Formaldehyde is used in embalming in mortuaries and in the preservation of medical and zoological specimens in spirit collections, and so occupational exposure through these routes is likely even with extraction systems.

\subsection{Endogenous Exposure of the Human Body to $C_{1}$ Compounds}

Per Sect. 2.1, in this section I have outlined some of the major routes by which the human body can be exposed to endogenous $\mathrm{C}_{1}$ compounds. Per my comments on Sect. 2.1, it is not intended to be exhaustive. 


\subsubsection{Oral Cavity}

The odor of the human oral cavity changes with diet, medication, sexual intercourse, and age. Oral malodor (halitosis) typically results from the production of DMS, $\mathrm{MeSH}$, carbon disulfide, MMA, DMA, TMA, and other volatiles (including methanol and some methane), particularly from Bacteria located in the periodontal pockets and on the rear of the tongue, as well as in the tonsillar crypts (Tonzetich 1973; Turner et al. 2006). Methylated selenium species (MeSeH and dimethylselenide) may potentially be present in the oral odor profile of persons consuming high-selenium diets or taking "selenium yeast" as a dietary supplement, but the examination of methylated selenium and tellurium species in the human body thus far has not been undertaken.

\subsubsection{Skin}

Human skin odor again, like that of the mouth, is subject to change and can contain methylated amines and methylated sulfur species. It also varies across the body, with those of the axillae and inguinal regions being particularly distinctive and varied by biological sex, age, hormone profile, hormone cycle position, sexual intercourse, exercise, adrenaline levels, medication, and diet. Full details of the odor of the skin and hair are given in Wood and Kelly (2010) in a previous edition of this handbook.

Bromhidrosis (offensive body odor) can be caused by overgrowth of Corynebacterium spp. and Micrococcus spp. The feet are also a cause of malodor, and, like all body odor, this is largely mediated by clothing (Callwewaert et al. 2014).

Various clinical conditions are associated with altered body or skin odor such as phenylketonuria (mouse or musty odor) or 2-oxoglutarate dehydrogenase complex deficiency (maple syrup or caramel odor). Some of these conditions result in $\mathrm{C}_{1}$ compound production such as hypermethioninemia or type I tyrosinemia (carbon disulfide and/or MeSH) and trimethylaminuria, which results in the inability of the body to oxidize TMA into TMAO, resulting in TMA secretion and a strong odor that may be fish-like or may just be unpleasant. This is present across the whole body, including the mouth and urine, but the skin is the largest source (Mitchell and Smith 2001). Similar effects are observed in dimethylglycinuria. The impacts of trimethylaminuria and dimethylglycinuria have been discussed by Wood et al. (2010) in a previous edition of this handbook. Gangrene and skin ulcers emit strong odors containing methylated amines, DMS, etc., also, but this has not been investigated in detail with respect to $\mathrm{C}_{1}$ compounds - DMTS has been found in some cancer-associated wounds (Shirasu et al. 2009). While not odorous, $\mathrm{DMSO}_{2}$ can be detected on the backs but not the arms of humans (Gallagher et al. 2008), which is interesting since $\mathrm{DMSO}_{2}$ is found in cerebrospinal fluid, particularly in the spine (Engelke et al. 2005).

\subsubsection{Genitalia}

The odor of the healthy female genital tract is dominated by fatty acids, which increases during arousal and following sexual intercourse. The odor of TMA may be present post-intercourse or after ovulation owing to bacterial activity, but is very strong during bacterial vaginosis (Wood et al. 2010) and sexually transmitted 
infections (Preti et al. 1978). TMA is not present in the odor profile of most healthy vaginae, pace immediately following menstruation in some individuals, as mentioned above (Wolrath et al. 2001). The odor profile of the neovagina of trans women is lower and subject to less discharge, and the flora largely resembles those of the anal canal or bacterial vaginosis flora (Weyers et al. 2009). Penile skin flora, particularly in uncircumcised males, produces TMA around the base of the glans, particularly if copious smegma is evident (Cold and Taylor 1999). There is a paucity of data on the odor of the neopenis in trans men.

\subsubsection{Gastrointestinal Tract}

The large intestine produces methane and a range of sulfur-containing gases such as DMS, MeSH, and hydrogen sulfide (Suarez et al. 1999). This varies with diet (Florin et al. 1991), with sulfur-rich and selenium-rich foods contributing MeSH, DMS, DMTS and DMDS, or MeSeH and dimethylselenol, respectively (Moore et al. 1987). The processes of their formation by anaerobic Bacteria and Archaea acting ultimately on cysteine, cystine, and methionine from digested proteins are analogous to the putrefaction of proteins in decaying animal tissue, in landfill, or in anoxic soils, which are outlined in Schäfer et al. (2010).

\section{$3 \quad$ Methylotrophs Known to Be Associated with the Human Body}

The first reports of methylotrophs associated with the human body as part of the normal flora were published by Dr. Ann P Wood's group (formerly of King's College London, UK) in the early part of this century and made use of both isolation and molecular methods. Since this pioneering work almost 20 years ago, there have been a considerable number of reports of human-associated methylotrophic Bacteria. As I discuss herein, there has been a considerable volume of work as a direct result of these studies at King's College London, which have now begun to lead to an understanding of the role of methylotrophs and methanotrophs from the normal flora in hollow organ and breast cancers and in various pathologies - it is of no doubt that those early studies regarding "Methylobacterium podarium" (now Methylorubrum podarium) will, in the fullness of time, directly lead to work that save lives.

Isolation of strains for characterization has been a core part of microbiology for over 100 years, and, while it is not as fashionable as metagenomics, etc., it is entirely necessary for obtaining evidence on enzyme biochemistry, evolution, etc., and some of the human-associated methylotrophs in pure culture are very well characterized, but we do not have genome sequences yet for any Methylorubrum podarium strains, for example. It is worth noting that there are a lot of studies in the last decade that produce a large number of isolates without any identification or characterization (e.g., feet and oral isolates from Waturangi et al. (2011) that were isolated on $24 \mathrm{mM}$ methanol), and while these libraries of organisms might be very useful to the community, it is really critical that proper identifications are made and deposits into international service collections are made before strains are lost. 
In this section I have covered three particularly interesting taxa in some detail and summarized the remainder of the work done, including some recent molecular ecological studies that have detected methylotroph presence.

\section{$4 \quad$ Methylobacterium and Methylorubrum spp.}

Methylobacterium spp. (Mbt.) are the archetypal "pink-pigmented facultative methylotroph" (PPFM) that one can easily isolate in the classical experiment of placing leaves on mineral salts agar for a few hours and then removing the leaves and incubating in an atmosphere of methanol vapor - they appear as salmon, pink, or orange colonies that fit the shape of the original leaf. Recently, Green and Ardley (2018) have proposed the reclassification of a large group of Methylobacterium spp. to Methylorubrum (Mrb.), a newly created genus (as shown in Fig. 1). Members of these genera are found in a myriad of environments including plants, bryophytes, and soils to more nutrient-poor environments such as drinking water (Methylobacterium adhaesivum (Gallego et al. 2006), Methylobacterium hispanicum and Methylobacterium aquaticum (Gallego et al. 2005a), and Methylobacterium isbiliense (Gallego et al. 2005b)), the air (Methylobacterium aerolatum and Methylobacterium iners, Weon et al. 2008), and fermented seafoods (Methylobacterium jeotgali Aslam et al. 2007) - all potential routes through which the human body could make contact and become colonized - but it is interesting to note that these taxa are not among those known to cause infection.

Methylobacterium spp. and Methylorubrum spp. are found in many bathrooms as pink or orange biofilms growing on tiling grout or on shower curtains and taking up $\mathrm{C}_{1}$ compounds found near to toilets. It has recently been proposed that the presence of Methylobacterium spp. and Methylorubrum spp. in bathroom biofilms corresponds to a lack of potentially pathogenic Mycobacterium spp. in said biofilms and that this could be a useful indicator (Falkinham et al. 2016).

\subsection{Role in Normal Human Flora}

From the feet of healthy volunteers, various strains of Methylorubrum podarium (basonym, Methylobacterium podarium) have been isolated. The type strain $\left(\mathrm{FM} 4^{\mathrm{T}}=\mathrm{DSM} 15083^{\mathrm{T}}=\right.$ ATCC BAA $\left.-547^{\mathrm{T}}\right)$ was isolated from a toe cleft. The cleft was swabbed with a sterile cotton swap which was used to inoculate an enrichment culture using $20 \mathrm{mM}$ MMA as the sole carbon source, from which the isolate was obtained on MMA agar. This pink-pigmented species grows on MMA, DMA, TMA, methanol, MeSH, DMS, DMSO, $\mathrm{DMSO}_{2}$, formate, and a wide range of organic acids, alcohols, and sugars (Anesti et al. 2004).

Methylorubrum zatmanii (basonym, Methylobacterium zatmanii) PI-UM was isolated from the mouth of a patient with significant dental caries and periodontal disease by enrichment culture on $12 \mathrm{mM}$ methanol (Carvajal et al. 2011). Methylorubrum rhodesianum (basonym, Methylobacterium rhodesianum) was isolated from the front of the human scalp (Uy et al. 2013), and a further 


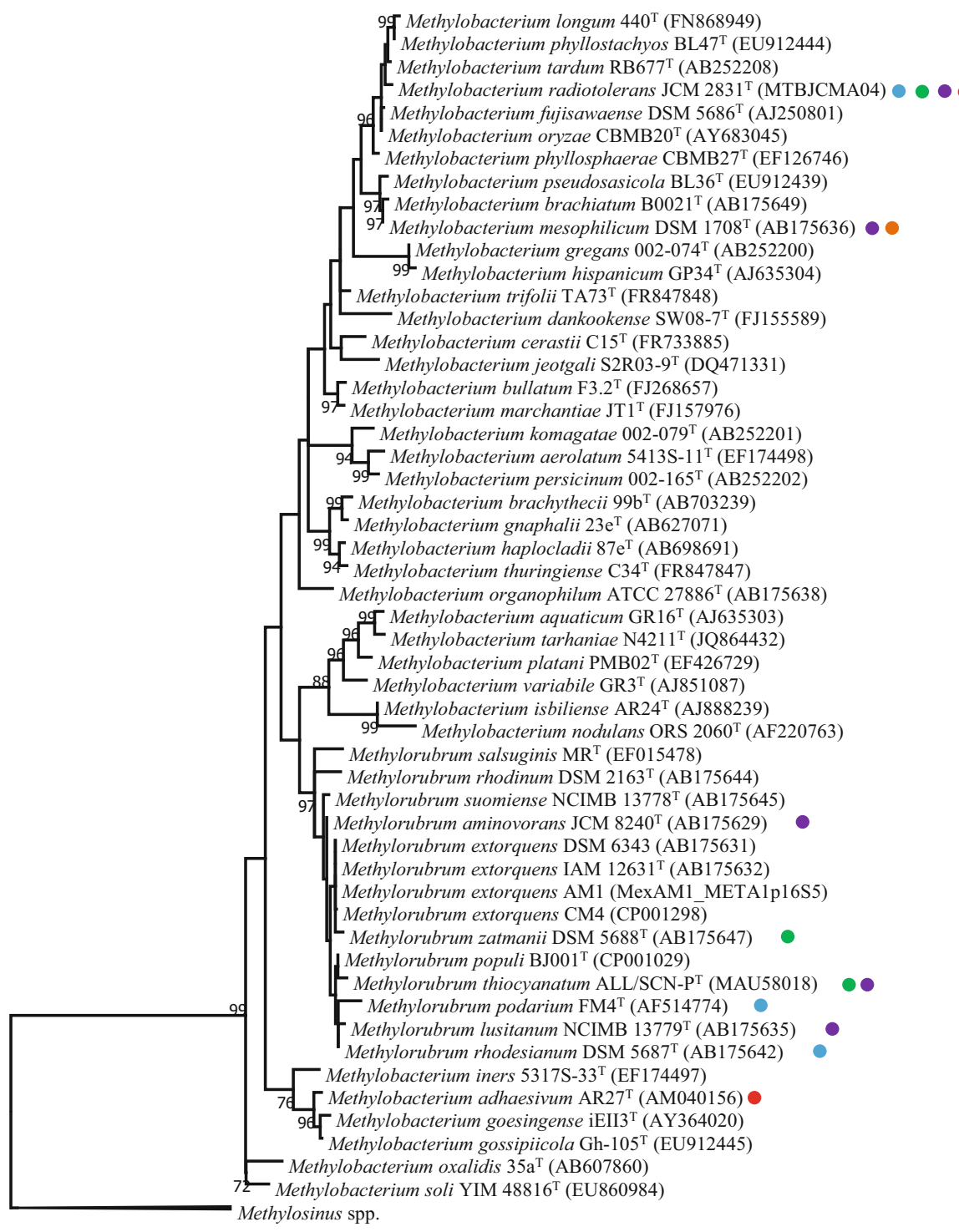

Fig. 1 Phylogenetic tree on the basis of the 16S rRNA ( $r r s$ ) gene, showing the positions of Methylobacterium spp. and Methylorubrum spp., using the sequences from Methylosinus spp. as the outgroup. Nucleotide sequences were aligned using MUSCLE (Edgar 2004) without use of any presets for speed that reduce accuracy. Aligned sequences were tested for best fit to models on the basis of the Bayesian information coefficient (BIC) in MEGA 7.0.26 (Kumar et al. 2016) and the trees reconstructed accordingly, using the Tamura-Nei model (Tamura and Nei 1993) with a discreet gamma distribution to model rate differences across sites (gamma parameter, 0.1439) and allowance for some sites to be evolutionarily invariable $(67.04 \%$ of sites). The tree shown is the optimal tree with the highest log-likelihood after 5,000 replications $(-18,617.15)$, with numbers at nodes indicating the percentage of 5,000 bootstrap replications in which the topology was preserved 
Methylobacterium or Methylorubrum sp. was isolated from the nasal vestibule (Uy et al. 2013). A strain of Methylobacterium radiotolerans was isolated from the naval (David and Diongzon 2013) - some properties of this strain are reviewed in Carvajal and Galvez (2015). Methylorubrum thiocyanatum (basonym, Methylobacterium thiocyanatum) and M. radiotolerans strains have been isolated from the human mouth (Anesti et al. 2005; Hung et al. 2011), as well as strains from the urinary tract (Lee et al. 2004). Lauder et al. (2016) detected Methylobacterium or Methylorubrum spp. on placental samples.

\subsection{Role as Human Pathogens}

In spite of Methylobacterium spp. being "workhorse" organisms in laboratories worldwide for many decades, they have recently been identified as opportunistic pathogens, before we fully understood that they were part of the normal flora in the seminal work of Wood, though we did have an understanding of their prevalence in human-associated environments, viz., their presence as $20 \%$ of the cultivable flora in dental unit waterlines (Barbeau et al. 1996). The first reports in the 1980s were of Methylobacterium mesophilicum in nosocomial infections (Gilardi and Faur 1984; Gilchrist et al. 1986; Rutherford et al. 1988; Smith et al. 1985) and later came reports of a patient given contaminated bone marrow (Brown et al. 1996) and in HIV patients with bacteremia (Truant et al. 1998). It is interesting to note that the type strain Mbt. mesophilicum ATCC $29983^{\mathrm{T}}$ was isolated from a leaf (Austin and Goodfellow 1979). The ability of this genus to form robust biofilms no doubt contributes to its prevalence in the environment and its pathogenicity (Kovaleva et al. 2014). Methylobacterium radiotolerans, Methylorubrum thiocyanatum, Methylorubrum aminovorans (basonym, Methylobacterium aminovorans), and Methylorubrum lusitanum strains have all been isolated from patients with hospital-acquired bacteremia (Lai et al. 2011). It is worth noting that Mrb. lusitanium is likely a heterotypic synonym of Mrb. rhodesianum (Kato et al. 2005).

Methylobacterium mesophilicum was included in the Vaginal Flora Microbial DNA qPCR Array (Qiagen 2013), indicating that the importance of this opportunistic pathogen and accurate diagnosis thereof has been accepted. Molecular

Fig. 1 (continued) (values $<70 \%$ omitted for clarity). All positions at which there was less than $95 \%$ coverage were omitted from the final analysis, in which 1,345 nt was used. Branch lengths are to scale and indicate the number of substitutions per site - bar represents 0.05 substitutions per site. Accession numbers are given in parentheses and refer to the GenBank database, unless they contain an underscore ("."), which designates that they are from the Integrated Microbial Genomes and Metagenomes (IMG/M) database. Type strains are indicated by a superscript "T" - multiple strains of Mbt. extorquens are included, viz., the "workhorse" strain AM1 and the various strains that grow on methyl halides, and were reclassified into this species. Colored dots indicate cyan, skin isolate; green, mouth isolate; orange, vaginal isolate; violet, opportunistic pathogen; red, associated with cancer 
ecological methods have identified methylotrophs in the vagina during bacterial vaginosis (Wood et al. 2010) and in sex workers (Schellenberg et al. 2011). Transcripts from Methylobacterium spp. and Methylorubrum spp. were found albeit in relatively small numbers in both women with bacterial vaginosis about to undergo treatment with $200 \mathrm{mg}$ lactoferrin applied per vagina, and in women after treatment with $100 \mathrm{mg}$ lactoferrin, which restored this genus that was not easily detected in the pretreatment state (Pino et al. 2017).

\subsection{Potential Roles in Breast Cancer}

Recently several links between Methylobacterium spp. or Methylorubrum spp. and breast cancers have been published. A decreased level of these genera in breast tissue and breast cancer was reported (Wang et al. 2017), suggesting that some compound they would typically degrade on/in the breast could reach the blood at higher levels when the organism is present in lower numbers, with potentially carcinogenic effects. It is hard to determine what that compound is since it may not be a $\mathrm{C}_{1}$ compound, owing to their facultative nature, but it is entirely plausible that, e.g., dimethyl sulfone taken orally could act as a probiotic, encouraging growth of Methylobacterium spp. or, more likely, Methylorubrum spp. on the skin and, potentially, in some way reducing cancer risk. That said, the Wang et al. (2017) study is one study: significantly more work needs to be undertaken before we can be certain of any role of these genera in cancer prevention, and given we know Methylobacterium spp. and Methylorubrum spp. are pathogenic, any proposed therapies need to be implemented with great caution and not used in immunocompromised individuals.

While the above Wang et al. (2017) study suggests Methylobacterium being depleting in number may be associated to breast cancer, Xuan et al. (2016) found the opposite. In their study, Methylobacterium radiotolerans was highly enriched in breast tissue, along with Sphingomonas yanoikuyae (we know that some Sphingomonas spp. grow methylotrophically, cf. Boden et al. 2008). Yadzi et al. (2016) evaluated the presence of these two species in sentinel lymph nodes removed at mastectomy from breast cancer patients, finding their presence to be much higher in nodes adjacent to stage 1 tumors than in controls (e.g., $97 \%$ of stage 1 tumor samples contained Mbt. radiotolerans or S. yanoikuyae DNA), and in stage 2 and stage 3 tumors, the levels of these two organisms were even higher.

The type strain of Methylobacterium radiotolerans $\left(\right.$ ATCC $27329^{\mathrm{T}}=\mathrm{NCIMB}$ $\left.10815^{\mathrm{T}}\right)$ was isolated from rice grains and tolerates $0.18 \mathrm{Mrad}(=1.8 \mathrm{kGy})$ doses of gamma radiation (Ito and Iizuka 1971) - if indeed this organism is involved in cancer causation, this could have implications in gamma radiotherapy, where local doses are in the region of $0.002 \mathrm{kGy}$ during breast cancer treatment (Hong et al. 2018), and would not kill the organism. The radiation tolerance mechanisms are probably an evolutionary adaptation to dehydration, in common with other radiation tolerant organisms and in keeping with its source of isolation in dehydrated rice (Musilova et al. 2015). Interestingly, the type strain of $S$. yanoikuyae $\left(\right.$ ATCC $51230^{\mathrm{T}}=\mathrm{DSM}$ 
$7462^{\mathrm{T}}$ ) was originally isolated from an unspecified clinical specimen, suggesting it may be prevalent on the human body (Yabuuchi et al. 1990).

Of course it is obvious that breast tumors - like many cancers - often become necrotic and emit MMA, DMA, TMA, DMS, MeSH, DMDS, DMTS, and other pungent volatiles (Warnke et al. 2003; Shirasu et al. 2009); the Methylobacterium spp. present may simply be "mopping up" these compounds and may have absolutely no role in cancer.

\subsection{Potential Roles of Methylobacterium spp. and Methylorubrum spp. in Other Cancers}

Methylobacterium spp. or Methylorubrum spp. were found to be enriched in number in cancerous tissue of colorectal cancer patients versus controls (Chen et al. 2012) and in gastric cancer patients - specifically Mbt. adhaesivum in the latter case (Castaño-Rodriguez et al. 2017). It is worth noting that the type strain (CCM $7305^{\mathrm{T}}=$ CECT $7069^{\mathrm{T}}$ ) of Mbt. adhaesivum has been isolated from drinking water supplies (Gallego et al. 2006); thus the route of exposure to the stomach is easy to determine.

\subsection{Perspectives}

It is interesting to note that the pathogenic Methylobacterium spp. and Methylorubrum spp. are seemingly limited to a relatively small number of species. Figure 1 shows a maximum likelihood tree based on the 16S rRNA (rrs) gene of Methylobacterium spp. and Methylorubrum spp. using Methylosinus spp. as the outgroup. Full details of the tree algorithms, etc., are given in the legend to Fig. 1. It can be seen from Fig. 1 that the cancer-associated organisms are found in both genera but that the nonpathogenic skin, vagina, and mouth isolates are mostly relatively closely related - though some of these are agents of infection - and are members of Methylorubrum.

While findings on Methylobacterium and Methylorubrum and their associations with human cancers are interesting, there is, however, a major caveat that must always be upheld: findings from molecular-based studies probably need to be reinforced with isolation-based work. This is owing to the presence of contaminating biomass/DNA from these genera - and from other methylotrophs - being commonplace in DNA and RNA extraction and purification kits, as well as in other molecular ecology sundry items. Salter et al. (2014) gives a good overview of the relevant literature on these kits. Contamination of so-called "ultrapure" (filtered) water supplies with the same organisms is also well understood with the evidence base going back over 25 years now (e.g., Kulakov et al. 2002; McFeters et al. 1993) obviously glass-distilled water that has then been autoclaved may provide a suitable 
alternative as DNA/RNA would not be anticipated to distill over! It is critical that all molecular-only demonstrations of the presence of these organisms in the human body, particularly where their presence is then correlated with some pathology or other, are validated to show the presence of viable and/or isolable cells.

It is clear that a proper appraisal of (1) infectious agent status and (2) oncogenesis is needed in Methylobacterium spp. and Methylorubrum spp. as a priority - these species are handled worldwide in research laboratories and teaching laboratories, occur in domestic bathrooms, are found on the skin of probably most humans on the planet, and are potentially causative agents of infectious disease and cancer, but are not currently handled as such.

\section{$5 \quad$ Hyphomicrobium sulfonivorans}

Hyphomicrobium sulfonivorans $\mathrm{S}^{\mathrm{T}}$ (=ATCC BAA-113 ${ }^{\mathrm{T}}=\mathrm{DSM} 13863^{\mathrm{T}}$ ) was originally isolated from garden soil using $\mathrm{DMSO}_{2}$ as the sole carbon source; it also grows on other $\mathrm{C}_{1}$ sulfur compounds and amines and is very well characterized (Borodina et al. 2000, 2002; Boden et al. 2011). Hyphomicrobium spp. are prosthecate organisms that have holdfasts and form rosettes and flocks in culture and can adhere strongly to surfaces in biofilms. They are well known to grow in low-nutrient environments, and workers in most $\mathrm{C}_{1}$ research laboratories will be familiar with Hyphomicrobium spp. being found in the distilled water aspirator! H. sulfonivorans CT and DTg were isolated from the teeth and tongues of healthy volunteers (Anesti et al. 2005) using $2 \mathrm{mM}$ DMS as the sole carbon source. These strains can grow on DMS, DMSO, $\mathrm{DMSO}_{2}, \mathrm{MeSH}$, methanol, MMA, TMA, formaldehyde, and formate but not DMA. They also grow on a range of organic acids and sugars - it is thus difficult to know if they are actually "methylotrophing" when in the human mouth, though in all likelihood, they are probably assimilating a whole range of carbon sources at the same time when growing in situ versus our in vitro cultures on single substrates.

\section{Brevibacterium casei}

Brevibacterium casei 3Tg and 3S(a) were isolated from dental hospital patients with periodontal disease using $2 \mathrm{mM}$ DMS as the sole carbon source (Anesti et al. 2005). They grow on DMS, DMSO, MeSH, methanol, MMA, TMA, and formate but not DMA and grow on a range of organic acids, sugars, and complex media. Brevibacterium is not considered a "classical" methylotrophic genus; however, the first report was in Brevibacterium methylicum (Nešvera et al. 1991). Interestingly, the type strain B. casei DSM $20657^{\mathrm{T}}$ will grow on methanol, MMA, MeSH, and DMS (Anesti et al. 2005), demonstrating that methylotrophy is probably widespread in this species, if not this genus. Hung et al. (2011) isolated Brevibacterium spp. from the human mouth also. 


\section{$7 \quad$ Immune Modulation by Methylococcus capsulatus}

Methylococcus capsulatus (Mcc.) is probably the best studied obligate methanotroph. The type strain Texas ${ }^{T}$ was originally isolated from a sewer but has not been studied in much depth - the Bath strain has become the international workhorse methanotroph. It contains intracellular stacked membranes of the "type I" variety (bundles of disc-shaped vesicles in the middle of the cytoplasm); the dominant fatty acids are palmitic $\left(\mathrm{C}_{16: 0}\right)$ and palmitoleic $\left(\mathrm{C}_{16: 1}\right)$ acids. It uses 18methylene-ubiquinone- 8 as the major respiratory quinone, which is rather unusual in the Gammaproteobacteria but common in the Methylococcales. An excellent review of Methylococcus capsulatus general physiology and metabolic potential is that of Kelly et al. (2005).

While not a human isolate, freeze-dried, lysed methane-grown cells of the Bath strain (=NCIMB 11132) of Methylococcus capsulatus (albeit incorrectly described as a "soil bacterium" when it came from sulfidic groundwater!) have been shown to prevent inflammatory bowel disease in mouse models (Indrelid et al. 2017) and adhere to human dendritic cells, influencing their ability to produce cytokines, activate T cells, etc. Previous work by Christoffersen et al. (2015) showed that Mcc. capsulatus Bath reduced intestinal inflammation in animal models, and work by Kleiveland et al. (2013) showed that Mcc. capsulatus Bath reduced ulcerative colitis in animal models.

\section{$8 \quad$ Other Human Isolates and Isolation Work Biases}

In the oral work of Anesti et al. (2005), Micrococcus luteus and Variovorax paradoxus strains were isolated on $\mathrm{C}_{1}$ compounds. Further oral work by Hung et al. (2011) isolated Gordonia, Leifsonia, Microbacterium, Micrococcus, Rhodococcus, Achromobacter, Klebsiella, Pseudomonas, and Ralstonia strains on $\mathrm{C}_{1}$ compounds, growing variously on MSA, MMA, and $\mathrm{DMSO}_{2}$. All of these organisms are canonically "atypical" methylotrophs, but it is worth noting that the author has isolated DMA-using Mycobacterium fluoranthenivorans DSQ3 and Rhodococcus erythropolis DSQ4, TMA-using Pseudomonas mendocina, and MMA-using Brevibacterium casei MSQ5 (Boden et al. 2008) from river sediment, and there are many reports of Gram-positive methylotrophs.

These "noncanonical" methylotrophs are relatively easy to isolate, and it is worth noting that the media used for the studies of Boden et al. (2008), Hung et al. (2011), Borodina et al. (2000, 2002), and Anesti et al. (2004, 2005) were all using basal salts of ionic strength 1.12 M (determined according to Debye and Hückel (1923) using data from the above studies minus the carbon source) - this is a comparatively very high ionic strength relative to media used for Methylobacterium spp. or methanotrophs, for example, nitrate mineral salts (NMS) of Dalton and Whittenbury (1976) have an ionic strength of 0.11 M (using data from Smith and Murrell 2011), and "dilute" variations used for Methylocella spp. could be as low as $0.01 \mathrm{M}$. It is possible that using higher ionic strength media in future work could reveal the 
diversity of Gram-positive methylotrophs (and potentially methanotrophs), but similarly, use of lower ionic strength media in future human studies may help isolate "canonical" methylotrophs and methanotrophs.

\section{$9 \quad$ Research Needs}

1. The urgent assessment of pathogenicity, oncogenesis, mutagenesis, and teratogenesis in all Methylobacterium spp. and Methylorubrum spp. is held in the international service collections and potentially the rest of the Methylobacteriaceae, if not all of the Rhizobiales. This is necessary to fully understand the gamut of potential infections and cancers that these organisms are associated with, and to aid current and future patients with Methylobacterium or Methylorubrum infections and cancers but is also critical for the protection of laboratory workers worldwide. In the meantime, I strongly recommend all Methylobacterium and Methylorubrum spp. be treated as Containment Level 2 (CL2) organisms rather than their usual Containment Level 1 (CL1) handling until we know more about the potential hazards and risks. It would seem prudent to remove them from the teaching laboratory unless at CL2 level.

2. Reevaluation of molecular-only studies that associate Methylobacterium and Methylorubrum spp. with human cancers, demonstrating the presence of viable cells and ruling out kit/reagent contamination.

3. Reappraisal of methylotrophy in known human-associated Bacteria, particularly Gram-positive organisms from the class Actinobacteria. Isolation with higher ionic strength media may achieve this.

4. The normalization of workers assessing growth on methanol, MMA, etc., in all new bacterial isolates to help see the true diversity of methylotrophy.

5. An appraisal of methylotrophs and methanotrophs in the anal canal and perianal area since methane (and DMS, MeSH, etc.) and oxygen are present, and this environment should support growth.

6. Greater understanding of the role of Methylobacterium and Methylorubrum in breast cancer prevention - is it cause or effect? Does it only apply to the breast? What happens in other cancers? Does $\mathrm{DMSO}_{2}$ consumption reduce the risk or elevate of these types of cancer in model organisms?

Acknowledgments I thank Dr. Ann P Wood (formerly of King's College London, UK) for stimulating discussions on methylotrophy and human disease and Dr. Michael J Cox (Imperial College London, UK) for insight on methylotrophic contamination of molecular studies. I also thank Dr. Lee P Hutt (University of Plymouth, UK) for reading and commenting on the manuscript.

\section{References}

Amiri H (2007) Chemical composition and antibacterial activity of the essential oil of Allium jesdianum Boiss. \& Buhse from Iran. J Med Plants 6:39-44+65 
Anesti V, Vohra J, Goonetilleka S, McDonald IR, Sträubler B, Stackebrandt E, Kelly DP, Wood AP (2004) Molecular detection and isolation of facultatively methylotrophy, including Methylobacterium podarium sp. nov., from the human foot. Environ Microbiol 6:820-830

Anesti V, McDonald IR, Ramaswamy M, Wade WG, Kelly DP, Wood AP (2005) Isolation and molecular detection of methylotrophic bacteria occurring in the human mouth. Environ Microbiol 7:1227-1238

Aslam Z, Lee CS, Kim KH, Im WT, Ten LN, Lee ST (2007) Methylobacterium jeotgali sp. nov., a non-pigmented, facultatively methylotrophic bacterium isolated from jeotgal, a traditional Korean fermented seafood. Int J Syst Evol Microbiol 57:566-571

Austin B, Goodfellow M (1979) Pseudomonas mesophilica, a new species of pink bacteria isolated from leaf surfaces. Int J Syst Bacteriol 29:373-378

Barbeau J, Tanguay R, Faucher E, Avezard C, Trudel L, Côté L, Prévost A (1996) Multiparametric analysis of waterline contamination in dental units. Appl Environ Microbiol 62:3954-3959

Bellesia F, Pinetti A, Bianchi A, Tirillini B (1996) Volatile compounds of the white truffle (Tuber magnatum Pico) from Middle Italy. Flavour Fragr J 11:239-243

Bills DD, Keenan TW (1968) Dimethyl sulfide and its precursor in sweetcorn. J Agric Food Chem 16:643-645

Boden R, Thomas E, Savani P, Kelly DP, Wood AP (2008) Novel methylotrophic bacteria isolated from the River Thames (London, UK). Environ Microbiol 10:3225-3236

Boden R, Borodina E, Wood AP, Kelly DP, Murrell JC, Schäfer H (2011) Purification and characterization of dimethylsulfide monooxygenase from Hyphomicrobium sulfonivorans. J Bacteriol 193:1250-1258

Borodina E, Kelly DP, Rainey FA, Ward-Rainey NL, Wood AP (2000) Dimethylsulfone as a growth substrate for novel methylotrophic species of Hyphomicrobium and Arthrobacter. Arch Microbiol 173:425-437

Borodina E, Kelly DP, Schumann P, Rainey FA, Ward-Rainey NL, Wood AP (2002) Enzymes of dimethylsulfone metabolism and the phylogenetic characterization of the facultative methylotrophs Arthrobacter sulfonivorans sp. nov., Arthrobacter methylotrophus sp. nov., and Hyphomicrobium sulfonivorans sp. nov. Arch Microbiol 177:173-183

Brown MA, Green JN, Sandin RL, Heimenz JW, Sinnott JT (1996) Methylobacterium bacteremia after infusion with contaminated autologous bone marrow. Clin Infect Dis 23:1191-1192

Bystedt J, Swenne L, Aas HW (1959) Determination of trimethylamine oxide in fish muscle. J Sci Food Agric 10:301-304

Callwewaert C, De Maeseneire E, Kerckhof F-M, Verliefde A, van de Wiele T, Boon N (2014) Microbial odour profile of polyester and cotton clothes after a fitness session. Appl Environ Microbiol 80:6611-6619

Carvajal TM, Galvez JB (2015) Current research status on the biology of pink pigmented facultative methylotrophic (PPFM) bacteria belonging to the genus Methylobacterium in the Philippines. Philipp J Syst Biol 9

Carvajal TM, Tan RL, Lee AC (2011) Methylobacterium zatmanii, a pink pigmented facultative methylotrophic (PPFM) bacterium isolated from the human oral cavity. Philipp J Syst Biol 5:1-9

Castaño-Rodriguez N, Goh K-L, Fock KM, Mitchell HM, Kaakoush NO (2017) Dysbiosis of the microbiome in gastric carcinogenesis. Sci Rep 7:15957

Chen W, Liu F, Ling Z, Tong Z, Xiang C (2012) Human intestinal lumen and mucosa-associated microbiota in patients with colorectal cancer. PLoS One 7:e39743

Christoffersen TE, Olsen Hult LT, Solberg H, Bakke A, Kuczkowska K, Huseby E, Jacobsen M, Lea T, Kleiveland CR (2015) Effects of the non-commensal Methylococcus capsulatus Bath on mammalian immune cells. Mol Immunol 66:107-116

Cold CJ, Taylor JR (1999) The prepuce. Br J Urol 83:34-44

Dalton H, Whittenbury R (1976) The acetylene reduction technique as an assay for nitrogenase activity in the methane oxidizing bacterium Methylococcus capsulatus (Bath). Arch Microbiol 109:147-151 
David AKS, Diongzon NEM (2013) Phenotypic and genotypic characterization of pink pigmented facultative methylotrophic (PPFM) bacteria isolated from the human belly button. Undergraduate thesis, De La Salle University, Manila

Debye P, Hückel E (1923) Zur Theorie der Elektrolyte. I. Gefrierpunktserniedrigung und verwandte Erscheinungen. Phys Z 24:185-206

Edgar RC (2004) Multiple sequence alignment with high accuracy and high throughput. Nucleic Acids Res 32:1792-1797

Engel E, Baty C, LeCorre D, Souchen I, Martin N (2002) Flavor-active compounds potentially implicated in cooked cauliflower acceptance. J Agric Food Chem 50:6459-6467

Engelke UF, Tangerman A, Willemsen MA, Moskau D, Loss S, Mudd SH, Wevers RA (2005) Dimethyl sulfone in human cerebrospinal fluid and blood plasma confirmed by one-dimensional ${ }^{1} \mathrm{H}$ and two-dimensional ${ }^{1} \mathrm{H}_{-}{ }^{13} \mathrm{C}$ NMR. NMR Biomed 18(5):331-336

Falkinham JO 3rd, Williams MD, Kwait R, Lande L (2016) Methylobacterium spp. as an indicator for the presence or absence of Mycobacterium spp. Int J Mycobacteriol 5:240-243

Florin TG, Neale G, Gibson GR, Christi SU, Cummings JH (1991) Metabolism of dietary sulphate: absorption and excretion in humans. Gut 32:766-773

Gallagher M, Wysocki CJ, Leyden JJ, Spielman AI, Sun X, Preti G (2008) Analyses of volatile organic compounds from human skin. Br J Dermatol 159:780-791

Gallego V, García MT, Ventosa A (2005a) Methylobacterium hispanicum sp. nov. and Methylobacterium aquaticum sp. nov., isolated from drinking water. Int J Syst Evol Microbiol 55:281-287

Gallego V, García MT, Ventosa A (2005b) Methylobacterium isbiliense sp. nov., isolated from the drinking water system of Sevilla, Spain. Int J Syst Evol Microbiol 55:2333-2337

Gallego V, García MT, Ventosa A (2006) Methylobacterium adhaesivum sp. nov., a novel methylotrophic bacterium isolated from drinking water. Int J Syst Evol Microbiol 56:339-342

Gilardi GL, Faur YC (1984) Pseudomonas mesophilica and an unnamed taxon, clinical isolates of pink-pigmented oxidative bacteria. J Clin Microbiol 20:626-629

Gilchrist MJR, Kraft JA, Hammon JG, Connelly BL, Myers MG (1986) Detection of Pseudomonas mesophilica as a source of nosocomial infections in a bone marrow transplant unit. J Clin Microbiol 23:1052-1055

Green P, Ardley JK (2018) Review of the genus Methylobacterium and closely related organisms: a proposal that some Methylobacterium species be reclassified into a new genus, Methylorubrum gen. nov. Int J Syst Evol Microbiol 68:2727

Hoffman DR (2010) Ant venoms. Curr Opin Allergy Clin Immunol 10:342-346

Hong JC, Rahimy E, Gross CP, Shafman T, Hu X, Yu JB, Ross R, Finkelstein SE, Dosortez A, Park HS, Soulos PR, Evans SB (2018) Radiation dose and cardiac cancer risk in breast cancer treatment: an analysis of modern radiation therapy including community settings. Pract Radiat Oncol. https://doi.org/10.1016/j.prro.2017.07.005

Hung W-L, Wade WG, Boden R, Kelly DP, Wood AP (2011) Facultative methylotrophs from the human oral cavity and methylotrophy in strains of Gordonia, Leifsonia, and Microbacterium. Arch Microbiol 193:407-417

Indrelid S, Kleiveland C, Holst R, Jacobsen M, Lea T (2017) The soil bacterium Methylococcus capsulatus Bath interacts with human dendritic cells to modulate immune function. Front Microbiol 8:230

Ito H, Iizuka H (1971) Taxonomic studies on a radio-resistant Pseudomonas. J Agric Biol Chem 35:1566-1571

Kato Y, Ashara M, Arai D, Goto K, Yokata A (2005) Reclassification of Methylobacterium chloromethanicum and Methylobacterium dichloromethanicum as later subjective synonyms of Methylobacterium extorquens and of Methylobacterium lusitanum as a later subjective synonym of Methylobacterium rhodesianum. J Gen Appl Microbiol 51:287-299

Kelly DP, Anthony C, Murrell JC (2005) Insights into the obligate methanotroph Methylococcus capsulatus. Trends Microbiol 13:195-198 
Kim KY, Ko HJ, Kim HT, Kim YS, Roh YM, Lee CM, Kim HS, Kim CN (2007) Sulfuric odorous compounds emitted from pig-feeding operations. Atmos Environ 41:4811-4818

Klaessen C (2013) Casarett \& Doull's toxicology: the basic science of poisons, 8th edn. McGraw Hill, New York

Kleiveland CR, Hult LT, Spetalen S, Kaldhusdal M, Christoffersen TE, Bengtsson O, Romarheim OH, Jacobsen M, Lea T (2013) The noncommensal bacterium Methylococcus capsulatus (Bath) ameliorates dextran sulfate (sodium salt)-induced ulcerative colitis by influencing mechanisms essential for maintenance of the colonic barrier function. Appl Environ Microbiol 79:48-56

Kovaleva J, Degener JE, van der Mei HC (2014) Methylobacterium and its role in health care-associated infection. J Clin Microbiol 52:1317-1321

Kulakov LA, McAlister MB, Ogden KL, Larkin MJ, O'Hanlon JF (2002) Analysis of bacteria contaminating ultrapure water in industrial systems. Appl Environ Microbiol 68:1548-1555

Kumar S, Stecher G, Tamura K (2016) MEGA7: Molecular Evolutionary Genetic Analysis version 7.0 for bigger datasets. Mol Biol Evol 33:1870-1874

Lai C-C, Cheng A, Liu W-L, Tan C-K, Huang Y-T, Chung K-P, Lee M-R, Hsueh P-R (2011) Infections caused by unusual Methylobacterium species. J Clin Microbiol 49:3329-3331

Lauder AP, Roche AM, Sherrill-Mix S, Bailey A, Laughlin AL, Bittinger K, Leite R, Elovitz MA, Perry A, Bushman FD (2016) Comparison of placenta samples with contamination controls does not provide evidence for a distinct placenta microbiome. Microbiome 4:29

Lawson LD, Wang ZH, Hughes BG (1991) Identification and HPLC quantitation of the sulfides and dialk(en)yl thiosulfinates in commercial garlic products. Planta Med 57:363-370

Leach JM, Chung LTK (1982) Gas concentrations and occupational health in Kraft mills. TAPPI J 65:95-98

Lee C-H, Tang Y-F, Liu J-W (2004) Underdiagnosis of urinary tract infection caused by Methylobacterium species with current standard processing of urine culture and its clinical implications. J Med Microbiol 53:755-759

Leonardos G, Kendall D, Barnard N (1969) Odor threshold determination of 53 odorant chemicals. J Air Pollut Control Assoc 19:91-95

Lindinger W, Taucher J, Jordan A, Hansel A, Vogel W (1997) Endogenous production of methanol after the consumption of fruit. Alcohol Clin Exp Res 21:939-943

Ljunggren G, Norberg B (1948) On the effect and toxicity of dimethyl-sulphide, dimethylsulphoxide and methyl-mercaptan. Acta Physiol Scand 5:248-255

McFeters GA, Broadaway SC, Pyle BH, Egozy Y (1993) Distribution of bacteria within operating laboratory water purification systems. Appl Environ Microbiol 59:1410-1415

Mitchell SC, Smith RL (2001) Trimethylaminuria: the fish malodor syndrome. Drug Metab Dispos 29:517-521

Moore JG, Jessop LD, Osborne DN (1987) Gas-chromatographic and mass-spectrometric analysis of the odor of human feces. Gastroenterology 93:1321-1329

Musilova M, Wright G, Ward JM, Dartnell LR (2015) Isolation of radiation-resistant bacteria from Mars analog Antarctic dry valleys by preselection, and the correlation between radiation and desiccation resistance. Astrobiology 15:1076-1090

Nešvera J, Pátek M, Hochmannová J, Chibisova E, Sererijski I, Tsyganov T, Netrusov A (1991) Transformation of a new Gram-positive methylotroph, Brevibacterium methylicum, by plasmid DNA. Appl Microbiol Biotechnol 35:777-780

Pino A, Giunta G, Randazzo CL, Caruso S, Caggia C, Cianci A (2017) Bacterial biota of women with bacterial vaginosis treated with lactoferrin: an open prospective randomized trial. Microbial Ecol Health Dis 28:1357417

Preti G, Huggins GR, Bares J (1978) Analysis of human vaginal secretions by gas chromatographymass spectrometry. Isr J Chem 17:215-222

Qiagen (2013) Vaginal flora DNA qPCR array (BAID-1902ZRA) product information leaflet 
Rutherford PC, Narkowicz JE, Wood JC, Peel MM (1988) Peritonitis caused by Pseudomonas mesophilica in a patient undergoing continuous ambulatory peritoneal dialysis. J Clin Microbiol 26:2441-2443

Salter SJ, Cox MJ, Turek EM, Calus ST, Cookson WO, Moffatt MF, Turner P, Parkhill J, Loman NJ, Walker AW (2014) Reagent and laboratory contamination can critically impact sequence-based microbiome analyses. BMC Biol 12:87

Sanhueza E, Andreae MO (1991) Emission of formic acid and acetic acids from tropical Savanna soils. Geophys Res Lett 18:1707-1710

Schäfer H, Myronova N, Boden R (2010) Microbial degradation of dimethylsulphide and related $\mathrm{C}_{1}$-sulphur compounds: organisms and pathways controlling fluxes of sulphur in the biosphere.

J Exp Bot 61:315-334

Schellenberg JJ, Links MG, Hill JE, Dumonceaux TJ, Kimani J, Jaoko W, Wachihi C, Mungai JN, Peters GA, Tyler S, Graham M, Severini A, Fowke KR, Ball TB, Plummer FA (2011) Molecular detection of vaginal microbiota in East African commercial sex workers. Appl Environ Microbiol 77:4066-4074

Shirasu M, Nagai S, Hayashi R, Ochiai A, Touhara K (2009) Dimethyl trisulfide as a characteristic odor associated with fungating cancer wounds. Biosci Biotechnol Biochem 73:2117-2120

Smet E, Lens E, van Langenhove H (1998) Treatment of waste gases contaminated with odorous sulfur compounds. Crit Rev Environ Sci Technol 28:89-117

Smith TJ, Murrell JC (2011) Mutagenesis of soluble methane monooxygenase. Methods Enzymol 495:135-147

Smith SM, Eng RHK, Forrester C (1985) Pseudomonas mesophilica infections in humans. J Clin Microbiol 21:314-317

Suarez FL, Springfeld J, Levitt MD (1999) Identification of gases responsible for the odour of human flatus and evaluation of a device purported to reduce this odour. Gut 43:100-104

Talou T, Gaset A, Delmas M, Kulifaj M, Montant C (1990) Dimethyl sulfide: the secret for black truffle hunting by animals? Mycol Res 94:277-278

Tamura K, Nei M (1993) Estimation of the number of nucleotide substitutions in the control region of mitochondrial DNA in humans and chimpanzees. Mol Biol Evol 10:512-526

Tonzetich J (1973) The uptake and metabolism of 35 S-labeled volatile sulfur compounds by putrescent saliva. Biochem Med 7:52-60

Truant AL, Gulati R, Giger O, Satishchandran V, Caya JG (1998) Methylobacterium species: an increasingly important opportunistic pathogen. Lab Med 29:704-710

Turner C, Spanel P, Smith D (2006) A longitudinal study of methanol in the exhaled breath of healthy volunteers using selected ion flow tube mass spectrometry, SIFT-MS. Physiol Meas 27:637-648

Tymczyna L, Chmielowiec-Korzeniowska A, Drabik A, Skórska C, Sitkowska J, Cholewa G, Dutkiewicz J (2007) Efficacy of a novel biofilter in hatchery sanitation: II. Removal of odorogenous pollutants. Ann Agric Environ Med 14:151-157

Usha PR, Naidu MU (2004) Randomised, double-blind, parallel, placebo-controlled study of oral glucosamine, methylsulfonylmethane and their combination in osteoarthritis. Clin Drug Investig 24:353-363

Uy MM, Uy J, Castro CZR, Carvajal TM, Ho HT, Lee AC (2013) Pink pigmented facultative methylotrophic (PPFM) bacteria isolated from the human scale and nasal cavity. Philipp J Syst Biol 7:13-21

van Langenhove HR, van Wassenhove FA, Coppin JK, van Acker MR, Schamp NM (1982) Gas chromatography/mass spectrometry identification of organic volatiles contributing to rendering odors. Environ Sci Technol 16:883-886

Wang H, Altemus J, Niazi F, Green H, Calhoun BC, Sturgis C, Grobmyer SR, Eng C (2017) Breast tissue, oral and urinary microbiomes in breast cancer. Oncotarget 8:88122-88138

Warnke PH, Terheyden H, Açil Y, Springer IN, Sherry E, Reynolds M, Russo PAJ, Bredee JP, Podschun R (2003) Tumor smell reduction with antibacterial essential oils. Cancer 100:879-880 
Waturangi DE, Nicholas CD, Susanto DO, Suhartono MT (2011) Isolation and identification of methylotrophic bacteria producing methanol dehydrogenase from human feet and mouth. HAYATI J Biosci 18:11-15

Weon HY, Kim BY, Joa JH, Son JA, Song MH, Kwon SW, Go SJ, Yoon SH (2008) Methylobacterium iners sp. nov. and Methylobacterium aerolatum sp. nov., isolated from air samples in Korea. Int J Syst Evol Microbiol 58:93-96

Weyers S, Verstraelen H, Gerris J, Monstrey S, dos Santos Lopes Santiago G, Saerens B, De Backer E, Claeys G, Vaneechoutte M, Verhelst R (2009) Microflora of the penile skinlined neovagina of transsexual women. BMC Microbiol 9:102

Williams MP (1973) Dimethyl sulfide: methodology, precursor kinetics and vegetable production evaluation. PhD thesis, Perdue University, USA

Wolrath H, Forsum U, Larsson PG, Borén H (2001) Analysis of bacterial vaginosis-related amines in vaginal fluid by gas chromatography and mass spectrometry. J Clin Microbiol 39:4026-4031

Wood AP, Kelly DP (2010) Skin microbiology, body odor, and methylotrophic bacteria. In: Timmis KN (ed) Handbook of hydrocarbon and lipid microbiology. Springer, Berlin

Wood AP, Warren FJ, Kelly DP (2010) Methylotrophic bacteria in trimethylaminuria and bacterial vaginosis. In: Timmis KN (ed) Handbook of hydrocarbon and lipid microbiology. Springer, Berlin

Xuan C, Shamonki JM, Chung A, DiNome ML, Chung M, Sieling PA, Lee DJ (2016) Microbial dysbiosis is associated with human breast cancer. PLoS One 9:e83744

Yabuuchi E, Yano I, Oyaizu H, Hashimoto Y, Ezaki T, Yamamoto H (1990) Proposals of Sphingomonas paucimobilis gen. nov. and comb. nov., Sphingomonas parapaucimobilis sp. nov., Sphingomonas yanoikuyae sp. nov., Sphingomonas adhaesiva sp. nov., Sphingomonas capsulata comb. nov., and two genospecies of the genus Sphingomonas. Microbiol Immunol 34:99-199

Yadzi HR, Movafagh A, Fallah F, Shargh SA, Mansouri N, Pour AH, Hashemi M (2016) Evaluation of Methylobacterium radiotolerance [sic.] and Sphingomonas yanoikuyae in sentinel lymph nodes of breast cancer cases. Asian Pac J Cancer Prev 17:279-285 